\title{
Apolipoprotein E polymorphism is associated with both number of diseased vessels and extent of coronary artery disease in Czech patients with CAD
}

\author{
Jan Machala ${ }^{a}$ Anna Vaskua, Ota Hlinomaz ${ }^{b}$, Petra Linhartovaa ${ }^{a}$ Ladislav Groch $^{b}$, Jiri Vitovec ${ }^{b}$
}

\begin{abstract}
Aims. The impact of ApoE polymorphism on angiographic parameters was assessed in patients referred for coronary angiography.

Methods. Elective coronary angiography was performed in 671 subjects ( 525 men, 146 women, mean age $60 \pm 10$ years) with symptoms of ischemic heart disease. The patients were divided into: no CAD group (smooth coronary vessels, $n=83)$, one-vessel $(n=155)$, two-vessel $(n=170)$ and three-vessel disease $(n=196)$. Patients with stenoses $0-50 \%$ were excluded. Within patients with CAD, we evaluated overall extent of CAD measured by the number of stenotic segments according to AHA (1 segment vs. $2-3$ vs. $\geq 4$ ), and the severity of the most serious stenosis (in percent). ApoE genotype was determined using real-time PCR.

Results. The frequency of $\varepsilon 2 / \varepsilon 3$ genotype ( $n=56$ ) was lower in the three-vessel disease group compared to one-vessel disease $(\mathrm{OR}=0.25, P=0.0019)$, two-vessel disease $(\mathrm{OR}=0.31, P=0.0114$ ) or no $\mathrm{CAD}$ group ( $\mathrm{OR}=0.24, P=0.0057)$. Frequency of $\varepsilon 2 / \varepsilon 3$ decreased with the number of affected segments ( 1 vs. $\geq 4$ : $O R=0.35, P=0.0143$ ). The $\varepsilon 3 / \varepsilon 4+\varepsilon 4 / \varepsilon 4$ genotypes $(n=123)$ were more frequent in CAD patients altogether compared with no $C A D$ group $(O R=2.30, P=0.019)$, while no impact of the $\varepsilon 4$ allele on angiographic parameters within the CAD patients was detected. In $\varepsilon 2 / \varepsilon 3$ carriers with CAD, lower LDL-cholesterol, total cholesterol and lower use of lipid-lowering drugs were observed.

Conclusions. The results show predominantly focal form of CAD in patients with $\varepsilon 2 / \varepsilon 3$ genotype. Lower LDL-cholesterol and total cholesterol may play the key role, although other contributing factors are discussed.
\end{abstract}

Key words: coronary artery disease, apolipoprotein E, coronary angiography, atherosclerosis, lipid-lowering treatment

Received: September 6, 2011; Accepted: April 25, 2012; Available online: June 1, 2012

http://dx.doi.org/10.5507/bp.2012.051

${ }^{a}$ Department of Pathophysiology, Faculty of Medicine, Masaryk University Brno, Czech Republic

${ }^{b} 7^{\text {st }}$ Department of Internal Medicine and Cardioangiology, International Clinical Research Center - ICRC, Faculty of Medicine, Masaryk University and St. Anne's University Hospital, Brno

Corresponding author: Jan Machal, e-mail:jmachal@med.muni.cz

\section{INTRODUCTION}

Coronary artery disease (CAD) is one of the leading causes of both morbidity and mortality in the industrialized world, being itself responsible for $24 \%$ of all deaths in the Czech Republic ${ }^{1}$. Numerous environmental and genetic factors have been described, including genes participating in lipid metabolism.

Apolipoprotein E (ApoE) is an important part of several types of lipoprotein particles, including chylomicrons, VLDL, IDL and ApoE-HDL. It is produced by hepatocytes in the liver, by macrophages in peripheral tissues and locally by glial cells in the brain ${ }^{2}$. The protein consists of 299 amino-acids. Its function is essential for lipid metabolism, at both systemic and local level. Among others, $\mathrm{ApoE}$ is a ligand of $\mathrm{LDL}(\mathrm{ApoE} / \mathrm{ApoB})$ receptor (LDL-R) (ref. ${ }^{3,4}$ ), contributing to chylomicron remnant and VLDL clearance ${ }^{5}$, and having numerous functions in vessel wall [reviewed in $\left(\right.$ ref. $\left.^{6}\right)$ ].

ApoE is produced by macrophages in diseased arterial wall during its inflammatory reaction, where it helps to carry away cholesterol in locally formed lipoproteins and reduce atherosclerotic plaque ${ }^{7,8}$. This effect can be also mediated by hepatic ApoE, as was proven in mice lacking macrophage-derived ApoE, and is responsible for anti-aterogenic action even without lowering plasma cholesterol levels ${ }^{9-11}$. The protein also induce the synthesis of $\mathrm{NO}$ in vessel wall ${ }^{12}$ and has numerous anti-inflammatory effects ${ }^{13,14}$

ApoE is polymorphic, with three isoforms common in general population: E2, E3 and E4. The three isoforms differ in two amino-acids at residues 112 and 158 of the protein. While E4 has arginine at both sites, E3 has cysteine at the first site and arginine at the second one and E2 has cysteine at both sites ${ }^{15,16}$. They are coded by three co-dominant alleles of apolipoprotein E gene (APOE) $\varepsilon 2$, $\varepsilon 3$ and $\varepsilon 4$, which give rise to 6 possible genotypes: $\varepsilon 2 /$ $\varepsilon 2$, $\varepsilon 2 / \varepsilon 3, \varepsilon 2 / \varepsilon 4, \varepsilon 3 / \varepsilon 3, \varepsilon 3 / \varepsilon 4$ and $\varepsilon 4 / \varepsilon 4$.

\section{Aim of the study}

We assessed the impact of ApoE polymorphism on the severity of CAD in patients referred for coronary angiography. CAD was defined as at least $50 \%$ stenosis of any segment of the coronary arteries. One, two and three- 
vessel disease group were defined by any major segment of LAD, LCx or RCA, affected by $\geq 50 \%$ stenosis. Patients with no narrowing of coronary arteries were used as control group, those with $<50 \%$ narrowing were excluded, as well as the patients with suspected vasospastic angina pectoris and patients after heart transplantation.

In subsequent analysis of patients with CAD, designed as case-case comparisons, we also focused on the association of the number of stenotic segments with ApoE genotypes, to determine the extent of CAD. The coronary artery tree was divided into segments according to the 16-segment scheme of the American Heart Association. Then, we divided the patients with CAD into 1 stenotic segment group (focal form of CAD), 2 or 3 stenotic segments group (medium form of CAD), and $\geq 4$ stenotic segments group (diffuse form of CAD) with similar numbers of patients.

In patients with CAD, we also investigated an impact of ApoE genotype on the severity of the most serious stenosis in coronary artery tree, expressed in percent of luminal obstruction in two dimensions.

The secondary aim was investigation of the levels of blood lipids and lipid-lowering medication, to determine possible effects of the ApoE isoform on blood lipids. The data on treatment were collected for all subjects, while the lipid spectrum was determined only in 382 (see results).

\section{MATERIAL AND METHODS}

\section{Coronary artery angiography}

Elective coronary angiography was performed in 671 consecutive patients of the $1^{\text {st }}$ Dep. Internal Med.\& Cardioangiology St. Anne's University Hospital in Brno, (525 men and 146 women, age median (lower-upper quartile) 58.5 years (52.9-67.9)) with the suspicion for ischemic heart disease (IHD). All subjects were of Caucasian descent. Indications for coronary angiography were IHD-like chest pain and/or results from non-invasive examinations supporting the diagnosis. The participants signed written consent prior to being taken into the study. Coronary angiograms were assessed by four experienced

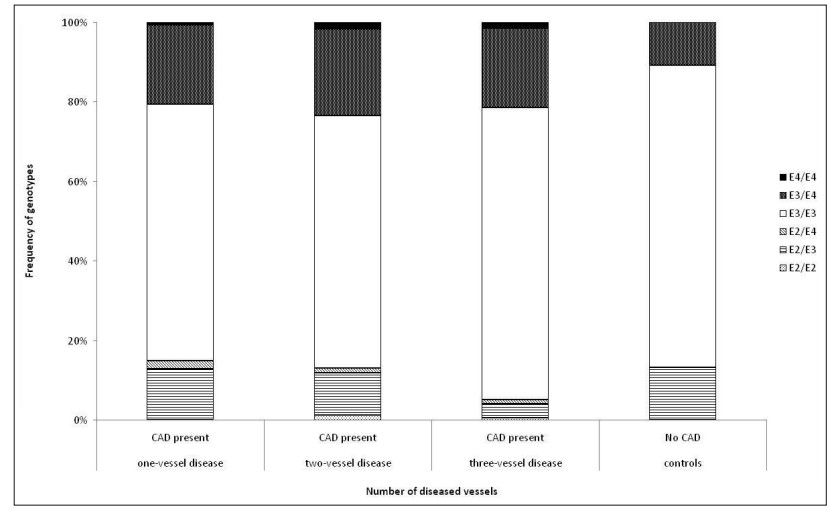

Fig. 1. Frequency of genotypes in one-, two- and three-vessel disease and in no CAD subjects. The graph shows significantly lower frequency of $\varepsilon 3 / \varepsilon 3$ genotype in three-vessel disease group compared to one-vessel disease and control group.

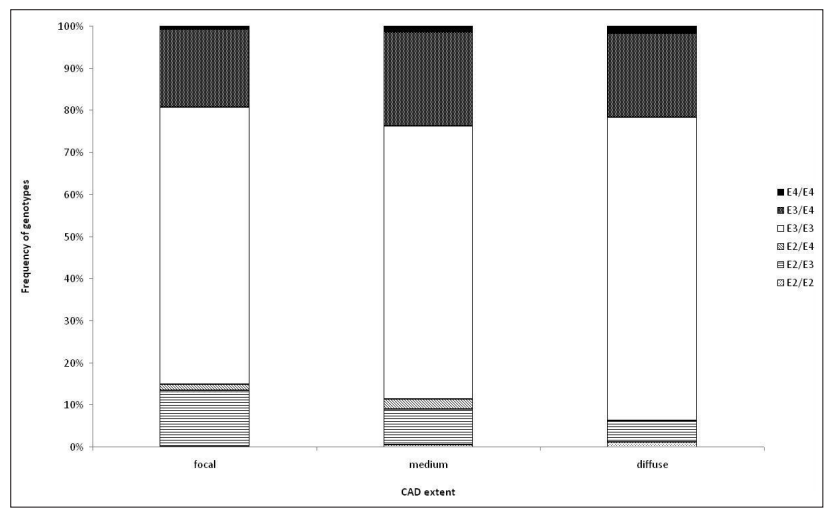

Fig. 2. Frequency of genotypes and the extent of CAD. The graph shows a decrease of $\varepsilon 3 / \varepsilon 3$ genotype frequency together wiht an increase of CAD extent.

invasive cardiologists. After the exclusions, we analysed 604 subjects, of whom 521 patients had CAD (155 in onevessel disease group, 170 in two-vessel disease group, 196 in three vessel-disease group). The control group (without any pathology of coronary vessels) was composed of 83 patients (Table 1.).

Table 1. Characteristics of the subjects.

\begin{tabular}{lcc}
\hline & Patients with CAD total & Controls \\
\hline Total/men & $531 / 441$ & $83 / 41$ \\
Age (years)* & $60.5(54.4-68.5)$ & $53.0(48.9-58.5)$ \\
BMI & $27.6 \pm 3.2$ & $27.6 \pm 3.9$ \\
Systolic blood pressure (mm Hg)* & $140(130-150)$ & $130(120-145)$ \\
Diastolic blood pressure (mm Hg* & $80(80-90)$ & $80(80-90)$ \\
Cholesterol (mmol/1) & $5.70 \pm 1.10$ & $5.48 \pm 0.92$ \\
HDL (mmol/1)* & $1.13(0.96-1.33)$ & $1.41(1.10-1.59)$ \\
LDL (mmol/l) & $3.64 \pm 1.05$ & $3.43 \pm 0.82$ \\
Triglycerides $(\mathrm{mmol} / 1)^{*}$ & $1.73(1.28-2.46)$ & $1.58(1.14-2.21)$ \\
Diabetes mellitus $(\mathrm{n} / \%$ of total & $122 / 23.0 \%$ & $10 / 12.0 \%$ \\
Ejection fraction $(\%)$ & $50 \%(44-60 \%)$ & $60 \%(56-65 \%)$ \\
\hline
\end{tabular}

All continuous variables with normal distribution are described as mean $\pm \mathrm{SD}$, those with non-normal distribution are marked * and the values represent median (lower-upper quartile). 


\section{Laboratory methods}

Genomic DNA was purified from peripheral blood leukocytes by the standard method using the phenol-chloroform extraction and the proteinase $\mathrm{K}$ digestion of cells.

Two single nucleotide polymorphisms (SNPs) in exon 4 at the positions rs429358 C/T (112 C/R) and rs7412 $\mathrm{C} / \mathrm{T}(158 \mathrm{C} / \mathrm{R})$ were analysed using Real-time polymerase chain reaction (RT-PCR) method monitored by SYBR ${ }^{\circledR}$ Green (ref. ${ }^{17}$ ). This method was optimized due to the formation of dimers which interfered with the analysis. Each RT-PCR was carried out in a volume $25 \mu \mathrm{L}$ containing 1x Power SYBR ${ }^{\circledR}$ Green PCR Master Mix (Applied Biosystems), $0.15 \mu \mathrm{M}$ of each primer and $50 \mathrm{ng}$ of genomic DNA. The lenght of the product was $173 \mathrm{bp}$. Four allele specific primers were combined in three reaction mixtures (Table 2,3). The amplification conditions were performed according to Calero et al. (ref. ${ }^{17}$ ), a Real Time PCR System (96-well format, ABI Prism 7000 Sequence Detection System, Applied Biosystems) was used. The real-time PCR took six following steps (Table 4).

The genotyping was performed without prior knowledge of the subject's status.

\section{Statistical analysis}

Statistical analysis was performed using STATISTICA software (StatSoft, version 11). Two-tailed Fisher exact test was used for categorical data, Mann-Whitney U-test for continuous data. Bonferroni test was used for multiple testing corrections, when comparing different groups of subjects. One-way ANOVA with Fisher's LSD post-test and t-tests were used for the comparison of blood lipids concentrations (HDL-cholesterol and triglycerides logtransformed to fit the normal distribution). Logistic re-

Table 2. Primers for real-time PCR.

\begin{tabular}{ll}
\hline Primers & Sequence \\
\hline ApoE_112C & $\begin{array}{l}\text { CGG ACA TGG AGG ACG TGT } \\
\text { - specific forward }{ }^{\circ} \mathrm{C}\end{array}$ \\
ApoE_112R & $\begin{array}{l}\text { CGG ACA TGG AGG ACG TGC } \\
\text { - specific forward }{ }^{\circ} \mathrm{C}\end{array}$ \\
ApoE_158C & CTG GTA CAC TGC CAG GCA \\
& $\begin{array}{l}\text { - specific reverse }{ }^{\circ} \mathrm{C} \\
\text { ApoE_158R }\end{array}$ \\
& CTG GTA CAC TGC CAG GCG \\
& specific reverse ${ }^{\circ} \mathrm{C}$ \\
\hline
\end{tabular}

gression was used for odds ratio and confidence intervals estimation.

In the statistical analyses, the $\varepsilon 3 / \varepsilon 4$ and $\varepsilon 4 / \varepsilon 4$ were included in one group, because low number of $\varepsilon 4 / \varepsilon 4$ carriers $(n=7)$ did not allow effective statistical analysis. The $\varepsilon 2 / \varepsilon 3$ carriers were, however, evaluated separately, because of large variability of both laboratory values and clinical expression in $\varepsilon 2 / \varepsilon 2$ homozygotes ${ }^{18,19}$.

\section{RESULTS}

The ApoE genotypes were consistent with being in Hardy-Weinberg equilibrium. The percentage of ApoE genotypes in the whole cohort was as follows: $\varepsilon 2 / \varepsilon 20.5 \%$,

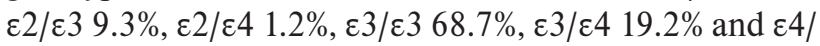
$\varepsilon 41.2 \%$. The composition of one-vessel disease, two-vessel disease, three-vessel disease and the control group is presented in the summary frequency table (Table 5, Fig. 1.).

The frequency of $\varepsilon 2 / \varepsilon 3$ decreased with increasing number of diseased arteries. We observed significantly lower frequency of $\varepsilon 2 / \varepsilon 3$ genotype in three-vessel disease group compared to one-vessel disease group $(\mathrm{OR}=0.25$, 95\% CI 0.10-0.61, $\left.P=0.0019, P_{\text {corr }}=0.011\right)$. The frequency was lower also compared to no CAD group ( $\mathrm{OR}=0.24$, 95\% CI 0.09-0.65, $P=0.0057, P_{\text {corr }}=0.034$ ).

The $\varepsilon 3 / \varepsilon 4$ and $\varepsilon 4 / \varepsilon 4$ genotypes were significantly more abundant in patients with CAD altogether compared with the no CAD group $(\mathrm{OR}=2.30,95 \% \mathrm{CI} 1.12-4.74, P=0.019$ for $\varepsilon 3 / \varepsilon 4+\varepsilon 4 / \varepsilon 4)$. However, no significant difference between the one-vessel, two-vessel and three-vessel disease group was observed.

In a subanalysis of the CAD group according to the number of stenotic segments, we could evaluate whether ApoE polymorphism has also an impact on extent of CAD in the patients with CAD (Table 6, Fig. 2).

The frequency of $\varepsilon 2 / \varepsilon 3$ genotype decreased with the extent of CAD, being significantly more frequent in a group with focal CAD compared to diffuse CAD ( $\mathrm{OR}=0.35$, 95\% CI 0.15-0.81, $\left.P=0.0143, P_{\text {corr }}=0.043\right)$. No association concerning $\varepsilon 3 / \varepsilon 4+\varepsilon 4 / \varepsilon 4$ carriers was observed.

No association between the severity of the most serious stenosis and ApoE genotype in patients with CAD was found, although there was an insignificant trend with $\varepsilon 3 / \varepsilon 4+\varepsilon 4 / \varepsilon 4$ genotypes being associated to more severe stenosis $(P=0.076)$.

Table 3. Mixture for qPCR $25 \mu \mathrm{L}$.

\begin{tabular}{lccc}
\hline \multicolumn{1}{c}{ Solution } & Reaction for $\varepsilon 2$ allele & Reaction for $\varepsilon 3$ allele & Reaction for $\varepsilon 4$ allele \\
\hline 1 x Power Syber Green PCR MM & $19.25 \mu \mathrm{L}$ & $19.25 \mu \mathrm{L}$ & $19.25 \mu \mathrm{L}$ \\
Primer ApoE_112C $(0.15 \mu \mathrm{M})$ & $0.375 \mu \mathrm{L}$ & $0.375 \mu \mathrm{L}$ & $0.375 \mu \mathrm{L}$ \\
Primer ApoE_112R $(0.15 \mu \mathrm{M})$ & & & $0.375 \mu \mathrm{L}$ \\
Primer ApoE_158C $(0.15 \mu \mathrm{M})$ & $0.375 \mu \mathrm{L}$ & $0.375 \mu \mathrm{L}$ \\
Primer ApoE_158R $(0.15 \mu \mathrm{M})$ & & \\
\hline $20 \mu \mathrm{LMM}+5 \mu \mathrm{L}$ of template DNA $(50 \mathrm{ng}$ in $5 \mu \mathrm{L})$ & & \\
\hline
\end{tabular}


Concerning the lipid spectrum, we found that subjects with $\varepsilon 2 / \varepsilon 3$ in the study showed lower total cholesterol compared to $\varepsilon 3 / \varepsilon 3(P=0.023)$ and $\varepsilon 3 / \varepsilon 4+\varepsilon 4 / \varepsilon 4$ $(P=0.020)$, and lower LDL-cholesterol compared to the same groups ( $\varepsilon 2 / \varepsilon 3$ vs. $\varepsilon 3 / \varepsilon 3: P=0.011$ vs., $\varepsilon 2 / \varepsilon 3$ vs. $\varepsilon 3 /$ $\varepsilon 4+\varepsilon 4 / \varepsilon 4: P=0.012$, respectively) (Table 7 ). $\varepsilon 2 / \varepsilon 3$ patients compared with the rest of our study group had lower total cholesterol ( $\varepsilon 2 / \varepsilon 3$ vs. other ApoE genotypes: $P=0.039$ for patients with CAD, $P=0.014$ for total sample) and LDLcholesterol ( $\varepsilon 2 / \varepsilon 3$ vs. other ApoE genotypes: $P=0.039$ for patients with CAD, $P=0.006$ for total sample) also when only CAD patients were assessed. This effect was apparent despite the fact that $\varepsilon 2 / \varepsilon 3$ carriers were less likely to

Table 4. Real-time PCR.

\begin{tabular}{ccc}
\hline Step & Temperature & Time \\
\hline 1 & $95{ }^{\circ} \mathrm{C}$ & $10 \mathrm{~min}$ \\
2 & $95{ }^{\circ} \mathrm{C}$ & $15 \mathrm{~s}$ \\
3 & $62{ }^{\circ} \mathrm{C}$ & $1 \mathrm{~min}$ \\
4 & $95{ }^{\circ} \mathrm{C}$ & $15 \mathrm{~s}$ \\
5 & $60{ }^{\circ} \mathrm{C}$ & $20 \mathrm{~s}$ \\
6 & $95{ }^{\circ} \mathrm{C}$ & $15 \mathrm{~s}$ \\
\hline
\end{tabular}

step 2) - 3) - repeat 40 times use lipid-lowering drugs, both among CAD patients and the total sample $(P=0.013$ for patients with CAD, $P=0.005$ for total sample), while no difference was observed in $\varepsilon 3 /$ $\varepsilon 4+\varepsilon 4 / \varepsilon 4$ concerning medication.

This study provides evidence, that $\mathrm{ApoE} \varepsilon 2 / \varepsilon 3$ genotype is associated not only with lower number of coronary arteries affected, but also with overall less extended form of coronary atherosclerosis, measured by the number of segments affected. The ApoE $\varepsilon 3 / \varepsilon 4+\varepsilon 4 / \varepsilon 4$ seems to be associated with $\mathrm{CAD}$ onset rather than extent. The lower concentration of LDL-cholesterol and total cholesterol is apparent in $\varepsilon 2 / \varepsilon 3$ subjects, although lipid-lowering treatment is less likely to be used in this group.

\section{DISCUSSION}

The association of ApoE to CAD has been described in many studies and meta-analyses. Compared to the most abundant $\varepsilon 3 / \varepsilon 3$ genotype, whose effects are considered neutral ${ }^{20}$, the ancestral ${ }^{21,22} \varepsilon 4$ allele has been found as a risk factor of CAD ( ref. $^{20,23,24}$ ), with previous studies giving it an important role ${ }^{25}$. Considered as "thrifty allele" 21 , the allele has been associated with elevated total cholesterol and low density lipoprotein cholesterol level ${ }^{26}$, which we

Table 5. Frequency of genotypes in one-, two- and three-vessel disease and in no CAD subjects.

\begin{tabular}{lccccccc}
\hline Group & $\varepsilon 2 / \varepsilon 2$ & $\varepsilon 2 / \varepsilon 3 *$ & $\varepsilon 2 / \varepsilon 4$ & $\varepsilon 3 / \varepsilon 3$ & $\varepsilon 3 / \varepsilon 4$ & $\varepsilon 4 / \varepsilon 4$ & Rows total \\
\hline No CAD & & 11 & & 63 & 9 & & 83 \\
& & $(13.3 \%)$ & & $(75.9 \%)$ & $(10.8 \%)$ & & $(100 \%)$ \\
\hline One-vessel disease & & 20 & 3 & 100 & 31 & 1 & 155 \\
& & $(12.9 \%)$ & $(19.4 \%)$ & $(64.5 \%)$ & $(20.0 \%)$ & $(0.6 \%)$ & $(100 \%)$ \\
Two-vessel disease & 2 & 18 & 2 & 108 & 37 & 3 & 170 \\
& $(1.2 \%)$ & $(10.5 \%)$ & $(1.2 \%)$ & $(63.5 \%)$ & $(21.7 \%)$ & $(1.8 \%)$ & $(100 \%)$ \\
Three-vessel disease & 1 & 7 & 2 & 144 & 39 & 3 & 196 \\
& $(0.5 \%)$ & $(3.6 \%)$ & $(1.0 \%)$ & $(73.5 \%)$ & $(19.9 \%)$ & $(1.5 \%)$ & $(100 \%)$ \\
CAD total & 3 & 45 & 7 & 352 & 107 & 7 & 521 \\
& $(0.6 \%)$ & $(8.6 \%)$ & $(1.3 \%)$ & $(67.6 \%)$ & $(20.5 \%)$ & $(1.3 \%)$ & $(100 \%)$ \\
\hline Columns total & 3 & 56 & 7 & 415 & 116 & 7 & 604 \\
& $(0.5 \%)$ & $(9.3 \%)$ & $(1.2 \%)$ & $(68.7 \%)$ & $(19.2 \%)$ & $(1.2 \%)$ & $(100 \%)$ \\
\hline
\end{tabular}

* The frequency of $\varepsilon 2 / \varepsilon 3$ genotype in three-vessel disease group was lower compared to one-vessel disease group (OR=0.25, 95\% CI 0.10-0.61, $P=0.0019$, $\left.P_{\text {corr }}=0.011\right)$ and also compared to no CAD group $\left(\mathrm{OR}=0.24,95 \% \mathrm{CI} 0.09-0.65, P=0.0057, P_{\text {corr }}=0.034\right)$.

Table 6. Frequency of ApoE genotypes and the extent of CAD.

\begin{tabular}{lccccccc}
\hline & & & \multicolumn{2}{c}{ Genotype } \\
CAD Extent & $\varepsilon 2 / \varepsilon 2$ & $\varepsilon 2 / \varepsilon 3 *$ & $\varepsilon 2 / \varepsilon 4$ & $\varepsilon 3 / \varepsilon 3$ & $\varepsilon 3 / \varepsilon 4$ & $\varepsilon 4 / \varepsilon 4$ & Rows total \\
\hline Focal & & $18(13.3 \%)$ & $2(1.5 \%)$ & $89(65.9 \%)$ & $25(18.5 \%)$ & $1(0.7 \%)$ & $135(100 \%)$ \\
Medium & $1(0.5 \%)$ & $18(8.5 \%)$ & $5(2.4 \%)$ & $137(64.9 \%)$ & $47(22.3 \%)$ & $3(1.4 \%)$ & $211(100 \%)$ \\
Diffuse & $2(1.1 \%)$ & $9(5.1 \%)$ & & $126(72.0 \%)$ & $35(20.0 \%)$ & $3(1.7 \%)$ & $175(100 \%)$ \\
\hline Columns total & $3(0.6 \%)$ & $45(8.6 \%)$ & $7(1.3 \%)$ & $352(67.6 \%)$ & $107(20.5 \%)$ & $7(1.3 \%)$ & $521(100 \%)$ \\
\hline
\end{tabular}

* The $\varepsilon 2 / \varepsilon 3$ genotype was significantly more frequent in a group with focal CAD compared to diffuse CAD

(OR=0.35, 95\% CI 0.15-0.81, $P=0.0143, P_{\text {corr }}=0.043$ ). 
Table 7. Blood lipids in the study group according to genotypes.

\begin{tabular}{lccccc}
\hline Genotype & $\varepsilon 2 / \varepsilon 2$ & $\varepsilon 2 / \varepsilon 3$ & $\varepsilon 2 / \varepsilon 4$ & $\varepsilon 3 / \varepsilon 3$ & $\varepsilon 3 / \varepsilon 4+\varepsilon 4 / \varepsilon 4$ \\
\hline $\mathrm{n}$ & 1 & 31 & 6 & 271 & 73 \\
Total cholesterol & 7.25 & $5.21 \pm 0.97 \dagger$ & $5.33 \pm 1.09$ & $5.69 \pm 1.12$ & $5.80 \pm 0.96$ \\
HDL-C * & 1.41 & $1.08(0.92-1.37)$ & $1.19(1.12-1.29)$ & $1.16(0.96-1.38)$ & $1.12(0.96-1.37)$ \\
LDL-C & 4.90 & $2.95 \pm 0.81 \dagger \dagger$ & $3.46 \pm 1.04$ & $3.64 \pm 1.09$ & $3.69 \pm 0.78$ \\
TAG * & 2.08 & $1.98(1.18-2.96)$ & $1.38(1.17-1.46)$ & $1.71(1.27-2.44)$ & $1.79(1.22-2.46)$ \\
\hline
\end{tabular}

All continuous variables with normal distribution are described as mean \pm SD, those with non-normal distribution are marked * and the values represent median (lower-upper quartile).

The value of total cholesterol marked $\dagger$ was lower in $\varepsilon 2 / \varepsilon 3$ compared to $\varepsilon 3 / \varepsilon 3(P=0.023)$ and to $\varepsilon 3 / \varepsilon 4+\varepsilon 4 / \varepsilon 4(P=0.020)$.

The value of LDL-cholesterol marked $\dagger \dagger$ was lower in $\varepsilon 2 / \varepsilon 3$ compared to $\varepsilon 3 / \varepsilon 3(P=0.011)$ and to $\varepsilon 3 / \varepsilon 4+\varepsilon 4 / \varepsilon 4(P=0.012)$.

Total cholesterol in $\varepsilon 2 / \varepsilon 3$ vs. all other ApoE genotypes: $P=0.039$ for patients with $C A D, P=0.014$ for total sample; LDL-cholesterol in $\varepsilon 2 / \varepsilon 3$ vs. all other ApoE genotypes: $P=0.039$ for patients with $\mathrm{CAD}, P=0.006$ for total sample.

failed to confirm in our study. Its risk potential for the development of CAD is commonly accepted, although negative effects on the development of atherosclerosis in heterozygous genotypes appear to be milder in recent large studies and meta-analyses, and possible publication bias is being discussed ${ }^{27-30}$.

The view of the role of $\varepsilon 2$ allele has been evolving across the decades. The homozygosis for $\varepsilon 2$ is crucial for the development of familial hyperlipoproteinemia type III (FH III), a disorder of lipid metabolism manifested by premature atherosclerosis ${ }^{5,18,31,32}$, which was historically the first disease linked to the polymorphism of ApoE (ref. ${ }^{33}$ ). However, the disease developes only under certain conditions, as is hyperinsulinemia, excessive caloric intake or male sex, while most of $\varepsilon 2 / \varepsilon 2$ homozygotes remain normolipidemic or hypolipidemic ${ }^{18,34}$. Generally, large variability in serum lipids concentration is typical for $\varepsilon 2 /$ $\varepsilon 2$ (ref. ${ }^{19,27}$ ). In our study group, there was only one $\varepsilon 2 / \varepsilon 2$ homozygote with completely determined lipid spectrum, a 68 year old patient showing lipid spectrum disorder with elevated cholesterol, LDL-cholesterol and triglycerides. Therefore we cannot confirm or reject the previous results.

In heterozygous genotypes $\varepsilon 2 / \varepsilon 3$ and $\varepsilon 2 / \varepsilon 4$, the $\varepsilon 2$ allele is considered protective against CAD (ref. ${ }^{19,27,30,35}$ ). The most apparent systemic effect is the lowering of LDL-C and total cholesterol in $\varepsilon 2 / \varepsilon 3$ (ref. ${ }^{26,27}$ ). Those characteristics, though not in that apparent way, seem to also take place in $\varepsilon 2 / \varepsilon 4$ heterozygotes, where the opposite effects of E2 and E4 isoforms are present ${ }^{27}$.

However, few studies have focused on the severity of CAD and length of atherosclerotic lesions ${ }^{36,37}$. The results of those studies are controversial however. Some found no correlation between the severity of CAD and ApoE polymorphism $^{38,39}$, while others established deleterious effect of ApoE4 isoform and protective effect of E2 isoform on the number of affected coronary vessels ${ }^{36,37}$ in various populations. The severity of stenoses has been found to follow the same manner in male Chinese ${ }^{37}$.

The overall extent of coronary atherosclerosis has been investigated mainly in autopsy studies that found $\varepsilon 3 /$ $\varepsilon 4$ genotype to be a risk factor for atherosclerosis extent, while no association in autopsy studies has been proven in $\varepsilon 2 / \varepsilon 3$ (ref. ${ }^{40,41}$ ). Low overall numbers of $\varepsilon 2 / \varepsilon 3$ carriers in those studies are possible explanation for the fact, that no significant changes in a frequency of $\varepsilon 2 / \varepsilon 3$ were observed. The in-vivo Brazilian study ${ }^{42}$ found no association of ApoE genotype and extent of atheromatosis. Our study, in contrast, suggest an effect of $\varepsilon 2 / \varepsilon 3$ genotype on lower extent of coronary artery disease, while it failed to prove any effect of $\varepsilon 4$ allele.

The influence of ApoE polymorphism on CAD can be largely attributed to the differential effect on lipid spectrum, as was proven in a large prospective study by Ward et al. ${ }^{30}$, on 22169 subjects. The study showed expected protective effect of $\varepsilon 2$ allele and mildly deleterious effect of $\varepsilon 4$ allele (which was of borderline significance), while it failed to show any significant effect after adjustment for LDL-C/HDL-C ratio.

Other, lipid-independent, mechanisms also exist. Concerning the systemic inflammatory response, the antiinflammatory effect of ApoE decreases in the sequence E2>E3>E4 [for review, see (ref. ${ }^{43}$ )]. Interestingly, concentration of serum CRP is isoform-specific in the opposite manner (E2>E3>E4) (ref. ${ }^{28,44}$ ), suggesting either some compensatory mechanism or just indirect involvement of CRP concentration in atherosclerosis.

Differential impact on the induction of endothelial nitric oxide synthase (eNOS) has also been described, eNOS being induced by isoforms E3>E2>E4 (ref. ${ }^{12}$ ). This order does not correspond with prevalence of CAD ( $\varepsilon 2 /$ $\varepsilon 3<\varepsilon 3 / \varepsilon 3<\varepsilon 3 / \varepsilon 4<\varepsilon 4 / \varepsilon 4$ ) (ref. ${ }^{27}$ ). The differential induction of eNOS might enhance the development of narrowing due to smooth muscle proliferation in the place of already formed lesions in $\varepsilon 2$ and $\varepsilon 4$ carriers, while their overall number and extent might be lower in $\varepsilon 2$ carriers because of their lower cholesterol and LDL-C. The eventual significance of this differential induction could be potentially demonstrated by combinatory effects of ApoE polymorphism and eNOS polymorphisms with known impact on CAD development, such as $4 \mathrm{a} / \mathrm{b}$ (ref. ${ }^{45,46}$ ).

The lower use of lipid-lowering treatment among subjects with $\varepsilon 2 / \varepsilon 3$ has been already described ${ }^{47}$ and is attributable to lower total cholesterol and LDL. The best 
response to statins and fibrates for lipid spectrum is present in the $\varepsilon 2$ carriers (ref. ${ }^{48,49}$ ), but the ApoE genotype does not seem to influence their effect on the progression of CAD ( ref. $^{50,51}$ ). Long-term prospective studies are needed for further evaluation.

Frequencies of ApoE genotypes in our group of CAD patients were, in general, consistent with other studies referring to ApoE and CAD performed in Central European populations including $\mathrm{Czech}^{28,39,52}$. The strengths and limitations of our control group are discussed further.

\section{Limitations and strengths}

The control group was recruited from selected patients referred for coronary angiography. Because of the strict conditions for admission to coronary angiography, the number of control subjects is much lower than patients with CAD. The genotype frequencies do not have to correspond with those present in healthy persons. Among others, possible presence of undiagnosed vasospastic angina (VSA) might have influenced the results. ApoE has been found to influence VSA occurrence in patients with smooth coronary arteries, with $\varepsilon 4$ allele being significantly less frequent in subjects with VSA compared to controls ${ }^{53}$. Although subjects with apparent VSA were excluded from our study, no specific test was used for the systematic search of VSA.

On the other hand, the way we selected the control group may also be regarded as strength. It may not be possible to distinguish patients with asymptomatic CAD or insignificant atherosclerosis in general population. A certain degree of atherosclerosis is not rare even in populations aged $<20$ years and is present in up to $85 \%$ in subjects aged $\geq 50$ years $^{54,55}$, which limits the use of asymptomatic randomly selected subjects as controls. Our control group consisted of individuals without any sign of atherosclerosis in the coronary angiograms, which eliminates any such undiagnosed patients or patients with mild forms of CAD. It is of interest, that ApoE $\varepsilon 3 /$ $\varepsilon 4+\varepsilon 4 / \varepsilon 4$ showed a trend to higher frequency in a group excluded for insignificant atherosclerosis compared to no CAD group $(P=0.033$, insignificant after Bonferroni correction). The subjects with insignificant atherosclerosis would probably remain inseparable from no CAD group if we used random population sample. An ideal, but unrealistic, way would be to perform coronary angiography in a sample of apparently healthy volunteers.

\section{CONCLUSION}

We revealed a significantly lower frequency of $\varepsilon 2 / \varepsilon 3$ genotype in patients with three-vessel disease and more diffuse form of coronary artery disease. The subjects with $\varepsilon 2 / \varepsilon 3$ differed in their lipid spectrum (with lower total cholesterol and LDL-cholesterol), despite being less likely to use lipid-lowering drugs. Lower extent of CAD could be thus explained by better lipid profile.

\section{ABBREVIATIONS}

ApoE, apolipoprotein E; APOE, apolipoprotein E gene; CAD, coronary artery disease; $\mathrm{CI}$, confidence interval; CRP, C-reactive protein; e-NOS, endothelial nitric oxide synthase; HDL, high-density lipoproteins; IHD, ischemic heart disease; IDL, intermediate-density lipoproteins; LAD, left anterior descendent artery, LCx, left circumflex artery; LDL, low-density lipoproteins; OR, odds ratio; RCA, right coronary artery; SNP, single nucleotide polymorphism; VLDL, very low-density lipoproteins; VSA, vasospastic angina.

\section{ACKNOWLEDGEMENT}

The study was supported by the Grant of the Internal Grant Agency of the Czech Republic IGA NS/10206$3 / 2009$.

\section{CONFLICT OF INTEREST STATEMENT}

Author's conflict of interest diclosure: The authors stated that there are no conflicts of interest regarding the publication of this article.

\section{REFERENCES}

1. CZSO. Czech Statistical Office - Deaths: by causes of death, sex and age. Available 16/05/2011 on URL: http://www.czso.cz/ csu/2010edicniplan.nsf/t/BC0030BE81/\$File/401910rg02.pdf2009

2. Boyles JK, Pitas RE, Wilson E, Mahley RW, Taylor JM. Apolipoprotein E associated with astrocytic glia of the central nervous system and with nonmyelinating glia of the peripheral nervous system. J Clin Invest 1985;76(4):1501-13. doi:10.1172/JCI112130

3. Innerarity TL, Pitas RE, Mahley RW. Receptor binding of cholesterolinduced high-density lipoproteins containing predominantly apoprotein $\mathrm{E}$ to cultured fibroblasts with mutations at the low-density lipoprotein receptor locus. Biochemistry 1980;19(18):4359-65.

4. Mahley RW, Hui DY, Innerarity TL, Weisgraber KH. Two independent lipoprotein receptors on hepatic membranes of dog, swine, and man. Apo-B,E and apo-E receptors. J Clin Invest 1981;68(5):1197-206.

5. Schneider WJ, Kovanen PT, Brown MS. Familial dysbetalipoproteinemia. Abnormal binding of mutant apoprotein E to low density lipoprotein receptors of human fibroblasts and membranes from liver and adrenal of rats, rabbits, and cows. J Clin Invest 1981;68(4):107585.

6. Kolovou GD, Anagnostopoulou KK. Apolipoprotein E polymorphism, age and coronary heart disease. Ageing Res Rev 2007;6(2):94-108. doi:10.1016/j.arr.2006.11.001

7. Basu SK, Brown MS, Ho YK, Havel RJ, Goldstein JL. Mouse macrophages synthesize and secrete a protein resembling apolipoprotein E. Proc Natl Acad Sci U S A 1981;78(12):7545-9.

8. Basu SK, Ho YK, Brown MS, Bilheimer DW, Anderson RG, Goldstein $J \mathrm{~L}$. Biochemical and genetic studies of the apoprotein $\mathrm{E}$ secreted by mouse macrophages and human monocytes. J Biol Chem 1982;257(16):9788-95.

9. Tsukamoto K, Tangirala RK, Chun S, Usher D, Puré E, Rader DJ. Hepatic expression of apolipoprotein $\mathrm{E}$ inhibits progression of atherosclerosis without reducing cholesterol levels in LDL receptor-deficient mice. Mol Ther 2000;1(2):189-94. doi:10.1006/mthe.2000.0028

10. Tangirala RK, Praticó D, FitzGerald GA. Reduction of isoprostanes and regression of advanced atherosclerosis by apolipoprotein E. J Biol Chem 2001;276(1):261-6. doi:10.1074/jbc.M003324200 
11. Raffai RL, Loeb SM, Weisgraber KH. Apolipoprotein E promotes the regression of atherosclerosis independently of lowering plasma cholesterol levels. Arterioscler Thromb Vasc Biol 2005;25(2):436-41. doi:10.1161/01.ATV.0000152613.83243.12

12. Sacre SM, Stannard AK, Owen JS. Apolipoprotein E (apoE) isoforms differentially induce nitric oxide production in endothelial cells. FEBS Lett 2003;540(1-3):181-7. doi: 10.1016/S0014-5793(03)00261-8

13. Ali K, Middleton M, Puré E, Rader DJ. Apolipoprotein E suppresses the type I inflammatory response in vivo. Circ Res 2005;97(9):922-7. doi:10.1161/01.RES.0000187467.67684.43

14. Baitsch D, Bock HH, Engel T. Apolipoprotein e induces antiinflammatory phenotype in macrophages. Arterioscler Thromb Vasc Biol 2011;31(5):1160-8. doi:10.1161/ATVBAHA.111.222745

15. Weisgraber KH, Rall SC, Mahley RW. Human E apoprotein heterogeneity. Cysteine-arginine interchanges in the amino acid sequence of the apo-E isoforms. J Biol Chem 1981;256(17):9077-83.

16. Rall SC, Weisgraber KH, Mahley RW. Human apolipoprotein E. The complete amino acid sequence. J Biol Chem 1982;257(8):4171-8.

17. Calero O, Hortigüela R, Bullido MJ, Calero M. Apolipoprotein E genotyping method by real time PCR, a fast and cost-effective alternative to the TaqMan and FRET assays. J Neurosci Methods 2009;183(2):238-40. doi:10.1016/j.jneumeth.2009.06.033

18. Mahley RW, Huang Y, Rall SC. Pathogenesis of type III hyperlipoproteinemia (dysbetalipoproteinemia). Questions, quandaries, and paradoxes. J Lipid Res 1999;40(11):1933-49.

19. Mamotte $C D$, Burke V, Taylor RR, van Bockxmeer FM. Evidence of reduced coronary artery disease risk for apolipoprotein epsilon $2 / 3$ heterozygotes. Eur J Intern Med 2002;13(4):250-5. doi: 10.1016/ S0953-6205(02)00030-4

20. Cumming AM, Robertson FW. Polymorphism at the apoprotein-E locus in relation to risk of coronary disease. Clin Genet 1984;25(4):310

21. Corbo RM, Scacchi R. Apolipoprotein E (APOE) allele distribution in the world. Is APOE*4 a 'thrifty' allele? Ann Hum Genet 1999;63(Pt 4):301-10.

22. Mahley RW, Rall SC. Is epsilon4 the ancestral human apoE allele? Neurobiol Aging 1999;20(4):429-30. doi: 10.1016/S01974580(99)00081-0

23. Kuusi T, Nieminen MS, Ehnholm C. Apoprotein E polymorphism and coronary artery disease. Increased prevalence of apolipoprotein E-4 in angiographically verified coronary patients. Arteriosclerosis 1989;9(2):237-41

24. Wilson PW, Schaefer EJ, Larson MG, Ordovas JM. Apolipoprotein E alleles and risk of coronary disease. A meta-analysis. Arterioscler Thromb Vasc Biol 1996;16(10):1250-5.

25. Song Y, Stampfer MJ, Liu S. Meta-analysis: apolipoprotein E genotypes and risk for coronary heart disease. Ann Intern Med 2004;141(2):137-47.

26. Eto M, Watanabe K, Ishii K. Reciprocal effects of apolipoprotein $E$ alleles (epsilon 2 and epsilon 4) on plasma lipid levels in normolipidemic subjects. Clin Genet 1986;29(6):477-84.

27. Bennet AM, Di Angelantonio E, Ye Z. Association of apolipoprotein E genotypes with lipid levels and coronary risk. JAMA 2007:298(11):1300-11. doi:10.1001/jama.298.11.1300

28. Grammer TB, Hoffmann MM, Renner W. Apolipoprotein E genotypes, circulating $\mathrm{C}$-reactive protein and angiographic coronary artery disease: The Ludwigshafen Risk and Cardiovascular Health Study. Atherosclerosis 2011;215(2):487-93. doi: 10.1016/j.atherosclerosis.2011.01.005

29. Sudlow C, Martínez González NA, Kim J, Clark C. Does apolipoprotein E genotype influence the risk of ischemic stroke, intracerebra hemorrhage, or subarachnoid hemorrhage? Systematic review and meta-analyses of 31 studies among 5961 cases and 17,965 controls. Stroke 2006;37(2):364-70. doi:10.1161/01.STR.0000199065.12908.62

30. Ward H, Mitrou PN, Bowman R. APOE genotype, lipids, and coronary heart disease risk: a prospective population study. Arch Intern Med 2009;169(15):1424-9. doi:10.1001/archinternmed.2009.234

31. Mahley RW. Apolipoprotein E: cholesterol transport protein with expanding role in cell biology. Science 1988;240(4852):622-30.

32. Brewer HB, Zech LA, Gregg RE, Schwartz D, Schaefer EJ. NIH conference. Type III hyperlipoproteinemia: diagnosis, molecular defects, pathology, and treatment. Ann Intern Med 1983;98(5 Pt 1):623-40.

33. Utermann G, Jaeschke M, Menzel J. Familial hyperlipoproteinemia type III: deficiency of a specific apolipoprotein (apo E-III) in the very-low-density lipoproteins. FEBS Lett 1975;56(2):352-355. doi:10.1016/0014-5793(75)81125-2

34. de Beer F, Stalenhoef AF, Hoogerbrugge N. Expression of type III hyperlipoproteinemia in apolipoprotein E2 (Arg158 --> Cys) homozygotes is associated with hyperinsulinemia. Arterioscler Thromb Vasc Biol 2002;22(2):294-9.

35. Menzel HJ, Kladetzky RG, Assmann G. Apolipoprotein E polymorphism and coronary artery disease. Arteriosclerosis 1983;3(4):310-5.

36. Wang XL, McCredie RM, Wilcken DE. Polymorphisms of the apolipoprotein $\mathrm{E}$ gene and severity of coronary artery disease defined by angiography. Arterioscler Thromb Vasc Biol 1995;15(8):1030-4.

37. Li SS, Yang J, Li LS, Wang HC. Apolipoprotein E polymorphism and the characteristics of diseased vessels in male Chinese patients with angiographic coronary artery disease: a case-case study. Clin Cardio 2010:33(6):E30-4. doi:10.1002/clc.20703

38. Reardon MF, Nestel PJ, Craig IH, Harper RW. Lipoprotein predictors of the severity of coronary artery disease in men and women. Circulation 1985;71(5):881-8.

39. Benes P, Muzik J, Benedik J. Single effects of apolipoprotein B, (a), and $E$ polymorphisms and interaction between plasminogen activator inhibitor-1 and apolipoprotein(a) genotypes and the risk of coronary artery disease in Czech male Caucasians. Molecular Genetics and Metabolism 2000:137-43.

40. Ilveskoski E, Perola M, Lehtimäki T. Age-dependent association of apolipoprotein $\mathrm{E}$ genotype with coronary and aortic atherosclerosis in middle-aged men: an autopsy study. Circulation 1999;100(6):60813.

41. Heide S, Manfred K, Gläser C, Schulz S. Apolipoprotein E (apoE) polymorphism: a risk factor for fatal coronary sclerosis? Forensic Sci Int 2009;192(1-3):62-6. doi:10.1016/j.forsciint.2009.07.020

42. Lima LM, Carvalho MG, Ferreira CN. Atheromatosis extent in coronary artery disease is not correlated with apolipoprotein-E polymorphism and its plasma levels, but associated with cognitive decline. Curr Alzheimer Res 2010;7(6):556-63.

43. Jofre-Monseny L, Minihane AM, Rimbach G. Impact of apoE genotype on oxidative stress, inflammation and disease risk. Mol Nutr Food Res 2008;52(1):131-45. doi:10.1002/mnfr.200700322

44. Golledge J, Biros E, Cooper M, Warrington N, Palmer LJ, Norman $\mathrm{PE}$. Apolipoprotein E genotype is associated with serum C-reactive protein but not abdominal aortic aneurysm. Atherosclerosis 2010;209(2):487-91. doi:10.1016/j.atherosclerosis.2009.09.027

45. Casas JP, Bautista LE, Humphries SE, Hingorani AD. Endothelial nitric oxide synthase genotype and ischemic heart disease: meta-analysis of 26 studies involving 23028 subjects. Circulation 2004;109(11):1359-65. doi:10.1161/01.CIR.0000121357.76910.A3

46. Kincl V, Vasků A, Meluzín J, Panovský R, Seménka J, Groch L. Association of the eNOS $4 \mathrm{a} / \mathrm{b}$ and $-786 \mathrm{~T} / \mathrm{C}$ polymormphisms with coronary artery disease, obesity and diabetes mellitus. Folia Biol (Praha) 2009;55(5):187-91.

47. Davies NM, Windmeijer F, Martin RM. Use of genotype frequencies in medicated groups to investigate prescribing practice: APOE and statins as a proof of principle. Clin Chem 2011;57(3):502-10. doi: 10.1373/clinchem.2010.156356

48. Christidis DS, Liberopoulos EN, Kakafika AI. The effect of apolipoprotein E polymorphism on the response to lipid-lowering treatment with atorvastatin or fenofibrate. J Cardiovasc Pharmacol Ther 2006;11(3):211-21. doi:10.1177/1074248406293732

49. Mega JL, Morrow DA, Brown A, Cannon CP, Sabatine MS. Identification of genetic variants associated with response to statin therapy. Arterioscler Thromb Vasc Biol 2009;29(9):1310-15. doi:10.1161/ATVBAHA.109.188474

50. Maitland-van der Zee $A H$, Jukema JW, Zwinderman $A H$ Apolipoprotein-E polymorphism and response to pravastatin in men with coronary artery disease (REGRESS). Acta Cardiol 2006;61(3):32731.

51. Ballantyne CM, Herd JA, Stein EA. Apolipoprotein E genotypes and response of plasma lipids and progression-regression of coronary atherosclerosis to lipid-lowering drug therapy. J Am Coll Cardiol 2000;36(5):1572-8. doi:10.1016/S0735-1097(00)00918-9

52. Balcerzyk A, Zak I, Krauze J. Synergistic effects of apolipoprotein E gene epsilon polymorphism and some conventional risk factors on premature ischaemic heart disease development. Kardiol Pol 2007;65(9):1058-65; discussion 1066-57. 
53. Kawakami K, Okumura K, Matsui H. The apolipoprotein E genotype influences the risk for vasospastic angina. Canadian Journal of Cardiology 2001:660-6.

54. Tuzcu E, Kapadia S, Tutar E. High prevalence of coronary atherosclerosis in asymptomatic teenagers and young adults - Evidence from intravascular ultrasound. Circulation 2001:2705-10.
55. Loecker T, Schwartz R, Cotta C, Hickman J. Fluoroscopic coronaryartery calcification and associated coronary-disease in asymptomatic young men. J Am Coll Cardiol 1992:1167-72. 